\title{
Four Lump Kinetics Models to Describe the Aromatization Reactions of Liquefied Petroleum Gas
}

\author{
Hongjun You*
}

Unit 86829 Center Street NW, Calgary, AB, T2K5C4, Canada

\begin{abstract}
The aromatization reaction of liquefied petroleum gas has been studied by using three liquefied petroleum gases as raw material and LBO-A as catalyst, and four lump kinetics models networks have been put up on the basis of lump theory and the aromatization reaction mechanism. In the network the aromatization reaction species was firstly lumped into $C_{4}$, propylene, low molecule hydrocarbon, liquid and coke. A mathematical method was first introduced to study on the product distribution of liquefied petroleum gas aromatization reaction. The results from experimental data are in accordance with the quantitatively analytical conclusions drawn from the calculated data.
\end{abstract}

Keywords: Four lumped kinetics, liquefied petroleum gas, aromatization reaction.

\section{INTRODUCTION}

In 1994, 1.27 hundred million tons of raw petroleum were processed, more than 2.2 million tons of ethylene were produced and the resources of liquefied petroleum gas reached approximately 3.7 million tons in China $[1,2]$. The resources of liquefied petroleum gas have become more and more abundant in China; the output of liquefied petroleum gas is more than 300 thousand tons per year $[3,4]$. The resources of liquefied petroleum gas are mainly from three resources in China, from the oil-gas field, the refinery and the gas crack $[5,6]$.

Nowadays the resources of liquefied petroleum gas are not completely applied, whereas most resources are burned as fuel $[7,8]$. Recently, research work focuses mainly on how to use liquefied petroleum gas effectively [9]. To study the effects of changing conditions of liquefied petroleum gas on its service performance [10-14], various quantitatively analytical methods have been developed, but the lumped kinetics models are seldom done.

In this paper, four lump kinetics models, which can predict aromatization reaction product distribution under various operating conditions and calculate the maximum deviations of the product yield between calculated results and practical values, are established for a confined fluidized bed reactor.

\section{EXPERIMENT}

\subsection{Experimental Material}

Huabei, Hua'ebin and Qilu are the liquefied petroleum gases which are obtained from a FCC unit of Huabei Petrochemical Company, Hua'ebin Petrochemical Company and Qilu Petrochemical Company, respectively. The components of three liquefied petroleum gases are shown in Table $\mathbf{1}$.

*Address correspondence to this author at the Unit 86829 Center Street NW, Calgary, AB, T2K5C4, Canada; Tel: (403) 275-7064;

E-mail: youhongjun@hotmail.com
Table 1. Components of Liquefied Petroleum Gas, wt \%

\begin{tabular}{|c|c|c|c|}
\hline Name & Huabei & Hua'ebin & Qilu \\
\hline \hline $\mathrm{C}_{3} \mathrm{H}_{8}$ & 0.23 & 0.05 & 0.07 \\
\hline $\mathrm{C}_{3} \mathrm{H}_{6}$ & 0.11 & 0.00 & 0.00 \\
\hline $\mathrm{i}-\mathrm{C}_{4} \mathrm{H}_{10}$ & 39.71 & 40.71 & 6.13 \\
\hline $\mathrm{n}-\mathrm{C}_{4} \mathrm{H}_{10}$ & 9.27 & 13.01 & 18.83 \\
\hline $\mathrm{t}-2$-butene & 13.56 & 13.05 & 28.94 \\
\hline $\mathrm{c}-2-$ butene & 8.36 & 7.84 & 17.70 \\
\hline $\mathrm{n}$-butene-1 & 11.91 & 11.07 & 12.56 \\
\hline i-butene & 16.54 & 13.50 & 15.42 \\
\hline $\mathrm{C}^{+}$ & 0.31 & 0.77 & 0.35 \\
\hline total & 100 & 100 & 100 \\
\hline
\end{tabular}

\subsection{Catalysts}

Catalyst (LBO-A) obtained from Lanzhou Petrochemical Institute is researched. LBO-A in a confined fluidized bed reactor was aged with $2 \mathrm{ml} / \mathrm{min}$ vapor at temperature $700^{\circ} \mathrm{C}$, $750^{\circ} \mathrm{C}$ or $800^{\circ} \mathrm{C}$, respectively. Its properties are presented in Table 2.

The micro-activity test index (MATI) is obtained by using the micro-reactor. The material oil provided by Beijing Petroleum Chemical Institute is light oil for the microreactor and its distillation range is from $225^{\circ} \mathrm{C}$ to $337^{\circ} \mathrm{C}$. The reaction temperature, time, inflow oil, catalyst weight in the micro-reactor all are stable, that is $460^{\circ} \mathrm{C}, 70 \mathrm{~s}, 1.56 \mathrm{~g}, 5.0030$ $\pm 0.0010 \mathrm{~g}$, respectively. By applying SP 3420 Gas Chromatograph the liquid product of above reaction is distillated and analyzed. MATI is given as follows:

$$
M=1-\frac{\left(m * W_{2}\right)}{m_{1}}
$$


where $M$ is MATI, \%; $m$ is liquid product weight, $\mathrm{g} ; m_{1}$ is total inflow oil weight, $\mathrm{g} ; W_{2}$ is the mass fraction of diesel oil in the liquid product.

Table 2. Properties of LBO-A Catalyst

\begin{tabular}{|c|c|}
\hline Parameters & Value \\
\hline \hline Apparent density, g/ml & 0.8 \\
\hline \multicolumn{2}{|c|}{ Particle size distribution, \% (by mass) } \\
\hline $0 \sim 45.8 \mu \mathrm{m}$ & 18.0 \\
\hline $45.8 \sim 111.0 \mu \mathrm{m}$ & 54.0 \\
\hline$>111.0 \mu \mathrm{m}$ & 28.0 \\
\hline Micro-activity test index (MATI) & 56 \\
\hline
\end{tabular}

\subsection{Experimental Method}

A confined fluidized bed reactor was applied in the aromatization reactions of liquefied petroleum gas and is shown in Fig. (1). It is consisted of five parts: oil and stream input system, reaction zone, temperature control, product separation and collection system. Variable amount of distilled water is pumped into the furnace to exchange into steam, and then mixed with liquefied petroleum gas pumped by another pump simultaneously at the outlet of a constant temperature box. The mixture is heated to approximately $420^{\circ} \mathrm{C}$ in a preheated room before it enters the reactor.

\subsection{Operating Condition}

The operating conditions for the aromatization reactions of liquefied petroleum gas are summarized in Table $\mathbf{3}$.

\subsection{Analytical Method}

An HP6890 Gas Chromatograph with Chem Station software is used to measure the volume percentage of aromatization gas components. These data are converted to mass percentage in the equation of state for ideal gases. The aromatization liquid was analyzed with TSY-1132 Liquid Petro- leum Hydrocarbon Measuring Equipment to obtain the mass percentage of n-paraffins, i-paraffins, naphthene, olefins and aromatics. The mass percentage of coke on catalyst was measured with KJ-02 Fast and Exact Measuring Coke Equipment.

Table 3. Operating Conditions for Liquefied Petroleum Gas

\begin{tabular}{|c|c|}
\hline Parameters & Value \\
\hline \hline Reaction temperature, ${ }^{\circ} \mathrm{C}$ & $450 \sim 500$ \\
\hline Weight hour space rate $(\mathrm{WHSV}), \mathrm{h}^{-1}$ & $2.0 \sim 6.5$ \\
\hline Water inflow, $\mathrm{ml} / \mathrm{min}$ & 2 \\
\hline LBO-A, $\mathrm{g}$ & 60 \\
\hline
\end{tabular}

\subsection{Experimental Principle [15]}

Low olefins $\left(\mathrm{C}_{2}=\mathrm{C}_{5}{ }^{=}\right)$and high olefins can exchange each other with catalyst.

This is not only reversible reaction but also gas phase reaction. The chemical Eq. (2) is shown as follows:

low olefins $\left(\mathrm{C}_{2}=\sim \mathrm{C}_{5}=\stackrel{\text { oligomerization }}{\text { cracking reaction }}\right.$ high olefins $\left(\mathrm{C}_{6}{ }^{+}\right)$

The cyclic reactions take place when high olefins $\left(\mathrm{C}_{6}{ }^{+}\right)$ and catalysts are in touch.

The chemical Eq. (3) is expressed as follows:

high olefins $\left(\mathrm{C}_{6}{ }^{+} \stackrel{\text { cyclic reaction }}{\longrightarrow}\right.$ cycloparaffinic hydrocarbon

Cycloparaffinic hydrocarbon and acerbity produce aromatics with catalyst.

The chemical Eq. (4) is shown as follows:

cycloparaffinic hydrocarbon $\stackrel{\text { hydrogenation }}{\longrightarrow}$ aromatics

The coking reactions take place when aromatics and n-

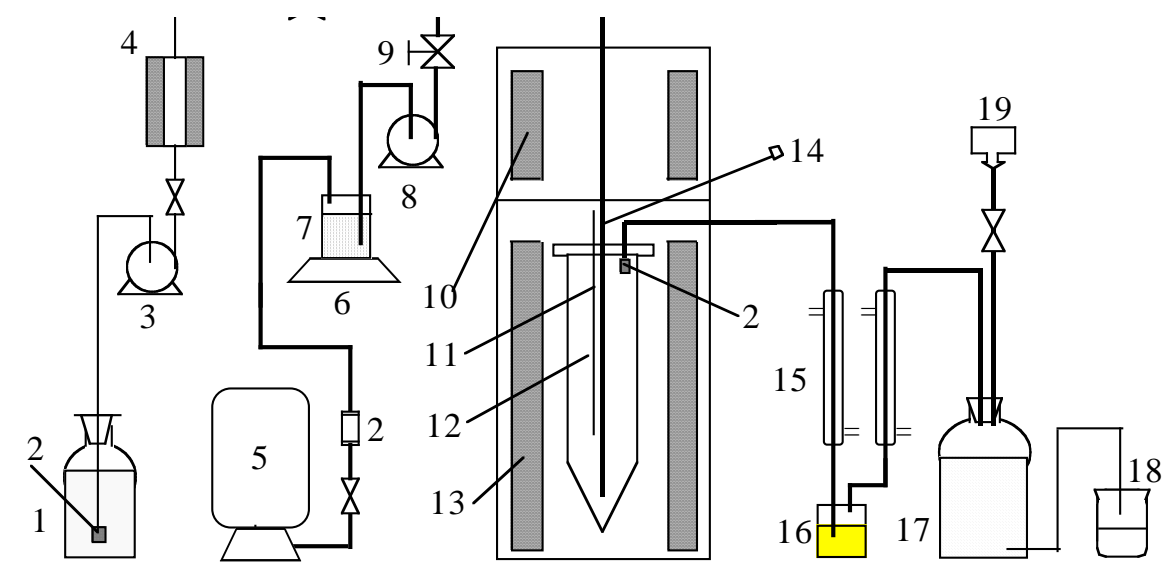

Fig. (1). Schematic drawing of experimental apparatus. 1-storage water tank ; 2-filter; 3-parallel pump; 4-steam boil; 5-C4 storage tank; 6-electronic balance; 7-C4 dampen tank; 8-peciprocating pump; 9-needle valve; 10-preheat boiler; 11-thermocouple; 12-reactor; 13-boiler; 14-catalyst inlet; 15- condenser; 16- liquid product collection bottle;17-collection gas bottle; 18-breaker; 19-gas sample bag. 
paraffins are in touch.

The chemical Eq. (5) is expressed as follows:
Liquefied petroleum gas going into infinitesimal is given as:

$c_{i} u \Omega d t$

\section{ESTABLISHING NINE LUMPED KINETICS MOD- ELS}

\subsection{Lumped Kinetics Models Scheme and Reaction Net- work}

According to the guiding principles of the lumped theory $[16,17]$ and based on the aromatization reaction mechanism [18-20], a new complex reaction network with four lumped kinetics models was proposed for the aromatization reaction of liquefied petroleum gas. In the network the aromatization reaction species were firstly lumped into $C_{4}$, propylene, low molecule hydrocarbon, liquid and coke. Four main type reactions among these lumped components were considered in the aromatization reaction network, such as olefins cyclization and dehydrogenation to aromatics, high olefins cracking to low olefins, low olefins oligomerization to high olefins, aromatics and n-paraffins coking to coke and so on. For the purpose of simplification, some reactions seldomly taken place and reactions of less importance were eliminated from the network. Its four lumps web models of liquefied petroleum gas studied on its reaction mechanism were shown in Fig. (2).

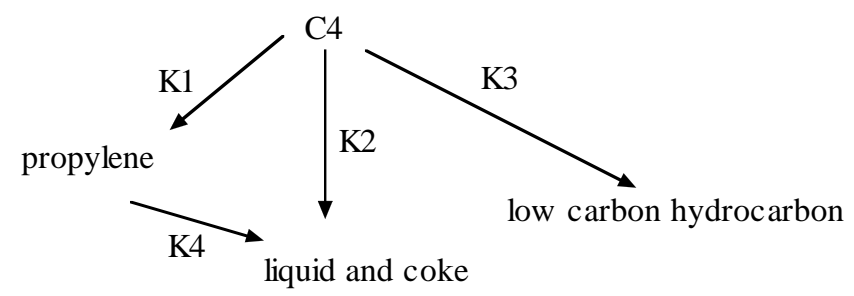

Fig. (2). Four lumps web models of liquefied petroleum gas.

\subsection{Mathematical Models}

It is supposed that all reaction equations of four lump reaction web models in the aromatization reaction of liquefied petroleum gas are first-order irreversible reaction. The performance of liquefied petroleum gas and catalyst in a confined fluidized bed reactor all are piston flow, non-axial diffusion, non-radial concentration and non-temperature gradient, and its reaction is controlled by the dynamic reaction and the effect of external-diffusion [21].

Lump $I$ becomes into lump $J$, and its Eq. (6) is expressed as follows:

$I \stackrel{k_{i j}}{\longrightarrow} v_{i i} J$

Component $i$ is calculated from high $x$ to $x+d x$ for a confined fluidized bed reactor.
Liquefied petroleum gas going out infinitesimal is:

$\left(c_{i}+d c_{j}\right)(u+d u) \Omega d t$

Material balance is given by:

$c_{i} u \Omega d t=\left(c_{j}+d c_{i}\right)(u+d u) \Omega d t+r_{i} \Omega d x d t$

Simplifies Eq. (9) as follows:

$u d c_{i}+c_{i} d u+d c_{i} d u=-r_{i} d x$

The infinitesimal liquefied petroleum gas's density remains unchanged based on the above assumption.

where $d u$ is defined as: $d u=0$

Using the above parameter simplifies Eq. (11) as follows:

$u \frac{d c_{j}}{d x}=-r_{j}$

Feed amount (liquefied petroleum gas and water vapor) $F_{0}(\mathrm{~kg} / \mathrm{s})$ is expressed as follows:

$F_{0}=u \Omega \rho$

and $\rho=\frac{p \overline{M W}}{R T}$

and $u=\frac{F_{0}}{\Omega} \cdot \frac{R T}{p \overline{M W}}$

Eq. (11) can be simplified by using the above equation as follows:

$\frac{d c_{j}}{d x}=-\frac{\Omega}{F_{0}} \cdot \frac{p \overline{M W}}{R T} r_{j}$

Component $i$ 's reaction rate [21] in the first-order reaction is calculated

$r_{i}=-k_{i}^{\prime} \rho_{c a t} c_{i}$

where $\rho_{\text {cat }}$ is parameter for catalyst, one obtains:

$$
\rho_{c a t}=\psi_{c / o} \rho
$$

By introducing Eq. (19) into Eq. (18), it may be given that:

$r_{i}=-k_{i}^{\prime} \psi_{c / o} \rho \cdot c_{i}$

Introducing Eqs. (12) and (18) into Eq. (15) yields: 


$$
\frac{d c_{j}}{d x}=\frac{p \overline{M W}}{R T} \psi_{c / o} \frac{1}{u} k_{j}^{\prime} c_{j}
$$

It is well known that catalyst's deactivation is caused by its surface coke. So it is supposed that catalyst's deactivation is the detention time function and is non-selective and all rate constant decrease with the same rate condition. Catalyst's deactivation function $\phi$ is a scalar and real rate con-

stant and $k_{j}^{\prime}$ is given as follows:

$k_{i}^{\prime}=k_{i} \phi\left(C_{c}\right)$

$\phi\left(C_{c 4}\right)=\exp \left(-\alpha C_{c 4}\right)$

By introducing Eqs. (20) and (21) into Eq. (19), it may be shown that:

$\frac{d c_{j}}{d x}=\frac{p \overline{M W}}{R T} \psi_{c / o} \frac{1}{u} k_{j} e^{-\alpha C_{C 4}} c_{j}$

A confined fluidized bed reactor's length is $L$ and dimensionless length is $X=x / L$. Simplifies Eq. (22) as follows:

$$
\begin{aligned}
& \frac{d c_{j}}{d X}=\frac{p \overline{M W}}{R T} \psi_{c / o} \frac{1}{u} L k_{j} e^{-\alpha C_{C 4}} c_{j} \\
& \frac{d c_{1}}{d X}=-\frac{p \overline{M W}}{R T} \psi_{c / o} \frac{1}{u} L\left(k_{1}+k_{2}+k_{3}\right) e^{-\alpha C_{C 4}} c_{1} \\
& \frac{d c_{2}}{d X}=\frac{p \overline{M W}}{R T} \psi_{c / o} \frac{1}{u} L\left[v_{12} k_{1} c_{1}-k_{4} c_{2}\right] \cdot e^{-\alpha C_{C 4}} \\
& \frac{d c_{3}}{d X}=\frac{p \overline{M W}}{R T} \psi_{c / o} \frac{1}{u} L\left(\cdot v_{23} k_{4} c_{2}+v_{13} k_{2} c_{1}\right) \cdot e^{-\alpha C_{C 4}} \\
& c_{4}=\left(1-c_{1} M_{1}-c_{2} M_{2}-c_{3} M_{3}\right) / M_{4}
\end{aligned}
$$

where $c_{i}$ is the concentration of component $i, \mathrm{kmol} / \mathrm{m}^{3} ; u$ is gasoline gas linear rate of a fluidized bed, $\mathrm{m} / \mathrm{s} ; \Omega$ is lateral section of a fluidized bed, $\mathrm{m}^{2} ; r_{i}$ is reaction rate of component $i, \mathrm{kmol} /\left(\mathrm{s} \cdot \mathrm{m}^{3}\right) ; \rho$ is gasoline gas density of a fluidized bed, $\mathrm{kg} / \mathrm{m}^{3} ; \quad p$ is reaction pressure, Mpa; $\overline{M W}$ is even relative molecular quality, $\mathrm{kg} ; R$ is gas constant; $T$ is reaction temperature, $\mathrm{K} ; \rho_{\text {cat }}$ is catalyst's density, $\mathrm{kg} / \mathrm{m}^{3}$; $\psi_{c / o}$ is mass ratio catalyst to oil; $\alpha$ is catalyst's deactivation constant; $t_{c}$ is catalyst's on-stream time, s; $L$ is reactor's high, $\mathrm{m} ; v_{i j}$ is chemistry measuring coefficient of lump $I$ becoming to lump $J ; k_{i j}$ is rate constant of lump $I$ becoming to lump $J ; M_{i}$ is relative molecule quality; $R_{w o}$ is mass ratio water to oil.

\subsection{Measuring Method of Deactivation Function}

Using a confined fluidized bed reactor and aromatization catalysts LBO-A, three liquefied petroleum gases (Huabei liquefied petroleum gas, Hua'ebin liquefied petroleum gas and Qilu liquefied petroleum gas) have been studied.
The liquefied petroleum gas material Z (C4's olefins content), reaction temperature ( $T$ ), liquefied petroleum gas' detention time $(t)$ and catalyst's detention time $\left(t_{c}\right)$ have an influence on the catalyst's coke yield $\left(C_{C 4}\right)$ in the aromatization reaction of $\mathrm{C} 4$ liquefied petroleum gas. The experimental data, reaction conditions and C4's olefins content are calculated to regress with the computer. The curve Eq. (29) of relationship between $C_{C 4}$ with C4's olefins content, reaction temperature, liquefied petroleum gas' detention time and catalyst's detention time are expressed as follows:

$$
C_{C 4}=38.766 \times\left[\begin{array}{l}
-0.19-0.3772 \cdot Z+0.0024 \\
T^{0.8771} \cdot t^{-0.062}
\end{array}\right] * t_{c}{ }^{0.0890} \cdot \%
$$

From Eq. (29), material quality and operation conditions have an important influence on the catalyst's coke yield. The catalyst's coke yield increases with an increase of C4's olefins content, reaction temperature and catalyst's detention time, but it decreases with an increase of liquefied petroleum gas' detention time.

$$
\left[-0.19-0.3772 \cdot Z+0.0024 \cdot T^{0.8771} \cdot t^{-0.062}\right] * t_{c}{ }^{0.0890} \quad \text { is }
$$

the material quality and operation conditions. The catalyst's coke yield will be calculated with the change of material quality and operation conditions based on the Eq. (29). And the calculated data and the experimental data will be contrasted in Fig. (3). The results from experimental data are in accordance with the quantitatively analytical conclusions drawn from the calculated data.

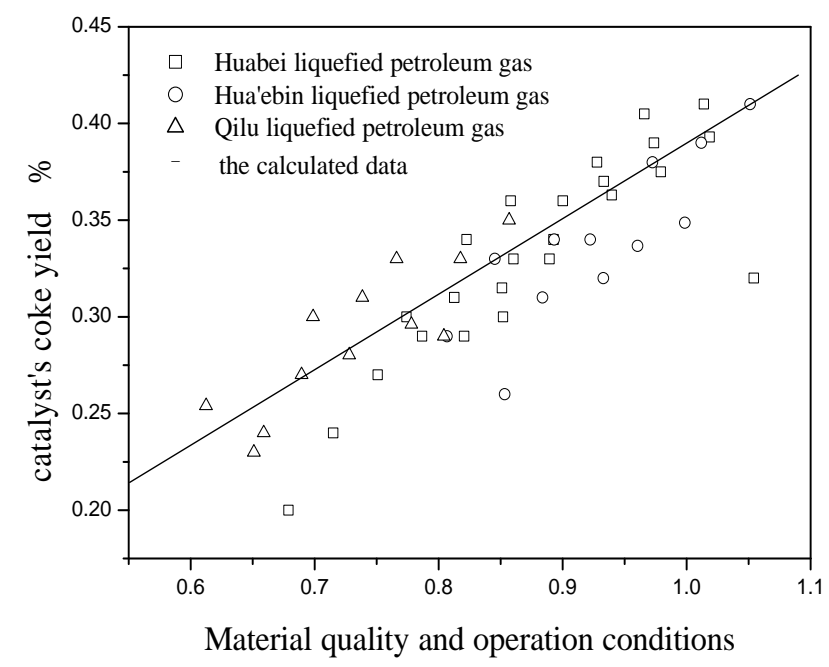

Fig. (3). The changeable trend of the catalyst's coke yield with material quality and operation conditions.

By introducing Eqs. (28) into Eq. (21), it may be shown that:

$\phi_{C 4}=\exp \left(-\alpha \cdot\left[\begin{array}{l}-0.19-0.3772 \cdot Z+ \\ 0.0024 \cdot T^{0.8771} \cdot t^{-0.062}\end{array}\right] * t_{c}{ }^{0.0890}\right)$

It is supposed that the catalyst deactivation constant $\alpha$ is an unchangeable constant with the increase of reaction temperature. On the other hand its deactivation function can apply for different liquefied petroleum gas because of includ- 
ing C4's olefins content. $\alpha$ 's value will be regressed based on the experimental data. So the liquefied petroleum gas deactivation function equation is obtained as follows:

$\phi_{C 4}=\exp \left(-0.56 \cdot\left[\begin{array}{l}-0.19-0.3772 \cdot Z+ \\ 0.0024 \cdot T^{0.8771} \cdot t^{-0.062}\end{array}\right] * t_{c}{ }^{0.0890}\right)$

\subsection{Measuring Method of Lumped Kinetics Models}

The numerical value result of lumped kinetics models are obtained by using modified Marquardt on the basis of Marquardt principle. The lumped kinetics function Eq. (31) is shown as follows:

$$
S(k)=\sum\left[y_{\exp }-y_{c a l}(t, c(t, k))\right]^{T} *\left[y_{\exp }-y_{c a l}(t, c(t, k))\right]
$$

where $\mathrm{k}$ is model parameter; $\mathrm{y}$ is variable; $\mathrm{c}$ is concentration; $\mathrm{T}$ is mathematical sign, vector matrix reversal; cal is calculated value; exp is experimental value, and where:

$y=\left(c_{1}, c_{2}, \ldots, c_{n}\right)^{T}$

is the concentration function.

$y_{c a l}$ is open at $k^{(0)}$ by using Taylor, and it is supposed that:

$\frac{\partial S(\Delta k)}{\partial \Delta k}=0$

Eq. (34) is given as follows:

$\sum\left|\frac{\partial c}{\partial k}\right|_{k^{(0)}}^{T}\left|\frac{\partial y_{c a l}}{\partial c}\right|_{k^{(0)}}^{T}\left|\frac{\partial y_{c a l}}{\partial c}\right|_{k^{(0)}}\left|\frac{\partial c}{\partial k}\right|_{k^{(0)}}$

$\cdot \Delta k=\sum\left|\frac{\partial c}{\partial k}\right|_{k^{(0)}}^{T}\left|\frac{\partial y_{c a l}}{\partial c}\right|_{k^{(0)}}^{T}\left[\left(y_{\exp }-y_{c a l}\left(t, k^{(0)}\right)\right)\right]$

By definition, $G=\frac{\partial y}{\partial a}, \Lambda=\frac{\partial a}{\partial k}$, may be shown to be:

$G=\left|\begin{array}{cccccc}0 & 1 & 0 & 0 & \ldots & 0 \\ 0 & 0 & 1 & 0 & \ldots & 0 \\ 0 & 0 & 0 & 1 & \ldots & 0 \\ \vdots & \vdots & \vdots & \vdots & \ddots & \vdots \\ 0 & 0 & 0 & 0 & \ldots & 1 \\ -\frac{M_{1}}{M_{n}} & -\frac{M_{2}}{M_{n}} & -\frac{M_{3}}{M_{n}} & -\frac{M_{4}}{M_{n}} & \ldots & -\frac{M_{n-1}}{M_{n}}\end{array}\right|$

The every unit of sensitive matrix can be solved in the difference method. Eq. (36) is shown as follows:

$\Lambda_{i j}=\left[a_{i}\left(k_{1}, k_{2}, \ldots, k_{j}+\Delta k_{j}, \ldots, k_{p}\right)-a_{i}\left(k_{1}, k_{2}, \ldots, k_{j}-\Delta k_{j}, \ldots, k_{p}\right)\right] / 2 \Delta k_{j}$

where $A$ and $b$ are defined as follows, respectively:

$A=\sum \Lambda^{T} G^{T} G \Lambda$

and $b=\sum \Lambda^{T} G^{T}\left[y_{\exp }-y_{c a l}\left(t, c\left(t, k^{(0)}\right)\right)\right]$

Using the above parameter simplifies Eq. (31) as follows:
$A * \Delta k=b$

After $\Delta k$ is solved, $k^{*}=k+\Delta k$ as the initial value will be computed until the number convergence.

\subsection{Experimental Result}

By using Huabei liquefied petroleum gas as a feedstock and LBO-A as catalysts and a confined fluidized bed as a reactor, the aromatization reaction of liquefied petroleum gas has been studied at $450^{\circ} \mathrm{C}, 475^{\circ} \mathrm{C}, 500^{\circ} \mathrm{C}$, respectively. The experimental results are listed in Tables $\mathbf{4 , 5}$ and $\mathbf{6}$.

Table 4. Yield of Four Lumped Compound at $450^{\circ} \mathrm{C}(\mathrm{wt} \%)$

\begin{tabular}{|c|c|c|c|c|c|}
\hline No. & WHSV & C4 & Propylene & $\begin{array}{c}\text { Liquid and } \\
\text { Coke }\end{array}$ & $\begin{array}{c}\text { Low Molecule } \\
\text { Hydrocarbon }\end{array}$ \\
\hline \hline 1 & 2.0 & 75.65 & 4.14 & 19.19 & 1.02 \\
\hline 2 & 2.5 & 79.02 & 4.13 & 16.02 & 0.83 \\
\hline 3 & 3.0 & 78.94 & 4.07 & 16.30 & 0.69 \\
\hline 4 & 3.5 & 78.80 & 4.02 & 16.59 & 0.61 \\
\hline 5 & 4.0 & 80.45 & 3.71 & 15.29 & 0.56 \\
\hline 6 & 4.5 & 79.26 & 4.01 & 16.25 & 0.48 \\
\hline 7 & 5.0 & 83.50 & 3.38 & 12.65 & 0.48 \\
\hline 8 & 5.5 & 82.54 & 3.26 & 13.80 & 0.39 \\
\hline 9 & 6.0 & 83.35 & 3.34 & 12.87 & 0.43 \\
\hline 10 & 6.5 & 85.84 & 2.90 & 10.86 & 0.40 \\
\hline
\end{tabular}

Table 5. Yield of Four Lumped Compound at $475^{\circ} \mathrm{C}(\mathrm{wt} \%)$

\begin{tabular}{|c|c|c|c|c|c|}
\hline No. & WHSV & C4 & Propylene & $\begin{array}{c}\text { Liquid and } \\
\text { Coke }\end{array}$ & $\begin{array}{c}\text { Low Molecule } \\
\text { Hydrocarbon }\end{array}$ \\
\hline \hline 1 & 2.0 & 77.44 & 4.05 & 17.27 & 1.23 \\
\hline 2 & 2.5 & 80.33 & 4.12 & 14.46 & 1.09 \\
\hline 3 & 3.0 & 79.46 & 4.36 & 15.29 & 0.88 \\
\hline 4 & 3.5 & 78.69 & 4.53 & 16.00 & 0.78 \\
\hline 5 & 4.0 & 80.70 & 4.07 & 14.49 & 0.74 \\
\hline 6 & 4.5 & 81.31 & 3.94 & 14.10 & 0.64 \\
\hline 7 & 5.0 & 83.89 & 3.44 & 12.07 & 0.60 \\
\hline 8 & 5.5 & 83.91 & 3.33 & 12.23 & 0.53 \\
\hline 9 & 6.0 & 83.27 & 3.36 & 12.89 & 0.47 \\
\hline 10 & 6.5 & 85.51 & 3.05 & 10.96 & 0.48 \\
\hline
\end{tabular}

\subsection{Resolved Lumped Kinetics Parameter}

The lumped kinetics parameters based on the above data are obtained by using matlab appliance procedure. The reaction rate constant in the temperature and active energy and frequency factor are shown in Tables $\mathbf{7}$ and $\mathbf{8}$, respectively.

Table 9 shows that the simulated values are near to the experimental values and the relative error values of product yield (C4, propylene, liquid and coke) are below 17\%. This 
indicts that the four lumped kinetics models can describe the product distribution of the liquefied petroleum gas aromatization reaction. But the relative error values of low molecule hydrocarbon is partly above $20 \%$, even reaches $52.93 \%$.

Table 6. Yield of Four Lumped Compound at $500^{\circ} \mathrm{C}(\mathrm{wt} \%)$

\begin{tabular}{|c|c|c|c|c|c|}
\hline No. & WHSV & C4 & Propylene & $\begin{array}{c}\text { Liquid } \\
\text { and Coke }\end{array}$ & $\begin{array}{c}\text { Low Molecule } \\
\text { Hydrocarbon }\end{array}$ \\
\hline \hline 1 & 2.0 & 79.24 & 3.96 & 15.35 & 1.45 \\
\hline 2 & 2.5 & 81.64 & 4.11 & 12.91 & 1.33 \\
\hline 3 & 3.0 & 79.99 & 4.66 & 14.28 & 1.07 \\
\hline 4 & 3.5 & 77.19 & 4.91 & 16.98 & 0.92 \\
\hline 5 & 4.0 & 80.94 & 4.43 & 13.70 & 0.91 \\
\hline 6 & 4.5 & 83.37 & 3.88 & 11.95 & 0.81 \\
\hline 7 & 5.0 & 84.28 & 3.51 & 11.49 & 0.72 \\
\hline 8 & 5.5 & 85.28 & 3.40 & 10.65 & 0.67 \\
\hline 9 & 6.0 & 83.19 & 3.37 & 12.92 & 0.52 \\
\hline 10 & 6.5 & 85.17 & 3.21 & 11.07 & 0.55 \\
\hline
\end{tabular}

\section{CONCLUSIONS}

In this paper, the author has found that the four lumped kinetics models lead to and are closely in accordance with predicting the practical experimental values. The yield of liquefied petroleum aromatization reactions can be accurately estimated. The four lump models point out that a deeply comprehending reaction mechanism of the aromatization of liquefied petroleum gas not only has a very important significance, but also provides a theoretical foundation for the chemical plant. It is important for the aromatization of liquefied petroleum gas to design and operate rightly and optimize the reaction processing and may increase the plant's benefits. This mathematical method is effective, eco- nomic, simple and convenient and thus it is suitable for refineries in China.

Table 7. Reaction Rate Constant of Four Lumped Models in the Different Temperature $\left((\mathrm{g} / \mathrm{cm} 3)^{-1} h^{-1}\right)$

\begin{tabular}{|c|c|c|c|}
\hline \multirow{2}{*}{ Reaction } & \multicolumn{3}{|c|}{ Reaction Temperature, ${ }^{\circ} \mathbf{C}$} \\
\cline { 2 - 4 } & $\mathbf{4 5 0}$ & $\mathbf{4 7 5}$ & $\mathbf{5 0 0}$ \\
\hline \hline $\mathrm{k} 1$ & 459.39 & 682.24 & 1102.52 \\
\hline $\mathrm{k} 2$ & 1664.86 & 2242.47 & 3308.57 \\
\hline $\mathrm{k} 3$ & 68.65 & 122.31 & 230.00 \\
\hline $\mathrm{k} 4$ & 46.46 & 49.98 & 59.50 \\
\hline
\end{tabular}

Table 8. Active Energy and Frequency Factor of Four Lumped Models

\begin{tabular}{|c|c|c|}
\hline Reaction & Active Energy KJ/mol & Frequency Factor $(\mathbf{g} / \mathbf{c m} 3)^{-\mathbf{1}} \mathbf{h}^{\mathbf{1}}$ \\
\hline \hline k1 & 81.81 & $3.73 \times 10^{8}$ \\
\hline k2 & 63.22 & $6.15 \times 10^{8}$ \\
\hline k3 & 13.53 & $6.52 \times 10^{6}$ \\
\hline k4 & 0.67 & $5.20 \times 10^{6}$ \\
\hline
\end{tabular}

\section{REFERENCES}

[1] Zhongqi, H. Discussion on compound C5 fraction appliance. Lanjian. Technol. China, 1995, 6, 142-5.

[2] Liyun, Z. Study on lower paraffin to aromatics. Yangtz Petrol. Chem. Industry (China), 1996, 11(3), 70-3.

[3] Hongjun, Y.; Chunming, X.; Jinsen, G. An orthogonal method for aromatization reactions of Shenghua liduefied petroleum gas. Petrol. Sci. Technol., 2007, 25, 759-72.

[4] Ligong, S. The research development on the aromatization of low petroleum gas. Fine Chem. (China), 1997, 14(2), 51-4.

[5] Jiajian, P.; Dagang L. Review of light hydrocarbon aromatization commercial technology. Petrol. Chem. Industry (China), 1996,

Table 9. Relative Error of Calculated Value and Experimental Value of Four Lumped Models at $500^{\circ} \mathrm{C}$

\begin{tabular}{|c|c|c|c|c|c|c|c|c|}
\hline \multirow{2}{*}{ No. } & \multicolumn{2}{|c|}{ C4 } & \multicolumn{2}{c|}{ Propylene } & \multicolumn{2}{|c|}{ Liquid and Coke } & \multicolumn{2}{|c|}{ Low Molecule Hydrocarbon } \\
\cline { 2 - 9 } & Cal. & Relative Error (\%) & Cal. & Relative Error (\%) & Cal. & Relative Error (\%) & Cal. & Relative Error (\%) \\
\hline \hline 1 & 78.15 & -1.39 & 4.62 & 16.56 & 16.15 & 5.21 & 1.08 & -25.35 \\
\hline 2 & 79.30 & -2.88 & 4.48 & 8.95 & 15.20 & 17.77 & 1.02 & -23.23 \\
\hline 3 & 80.23 & 0.31 & 4.34 & -6.77 & 14.48 & 1.35 & 0.98 & -8.73 \\
\hline 4 & 81.03 & 4.98 & 4.20 & -14.05 & 13.82 & -18.62 & 0.94 & 1.96 \\
\hline 5 & 81.73 & 0.97 & 4.09 & -7.73 & 13.28 & -3.10 & 0.90 & -1.19 \\
\hline 6 & 82.35 & -1.22 & 3.97 & 2.27 & 12.80 & 7.19 & 0.87 & 8.28 \\
\hline 7 & 82.90 & -1.63 & 3.87 & 10.28 & 12.38 & 7.80 & 0.85 & 16.99 \\
\hline 8 & 83.41 & -2.19 & 3.77 & 10.92 & 12.00 & 12.72 & 0.82 & 21.86 \\
\hline 9 & 83.87 & 0.81 & 3.68 & 9.22 & 11.66 & -9.74 & 0.80 & 52.93 \\
\hline 10 & 84.29 & -1.04 & 3.59 & 12.10 & 11.34 & 2.50 & 0.78 & 40.58 \\
\hline
\end{tabular}

Exp. = experimental value; Cal. = calculated value; low molecule hydrocarbon include $\mathrm{H}_{2}, \mathrm{CH}_{4}, \mathrm{C}_{2} \mathrm{H}_{4}, \mathrm{C}_{2} \mathrm{H}_{6}, \mathrm{C}_{3} \mathrm{H}_{6}$ and $\mathrm{C}_{3} \mathrm{H}_{8}$. 
25(4), 290-5.

[6] Ailin, Z. The progress of catalytic conversion of lower alkanes to aromatics. Chem. Times (China), 1998, 12(2), 7-11.

[7] Yanru, M. Propane aromatization over Pt-Ga/HZSM-5 catalyst. Develop. Appl. Energ. (China), 2002, 2, 47.

[8] Enshun, S. Bi-functional role of ZnHZSM-5 zeolite in the aromatization propane. Chem. Technol. (China), 1999, 7(3), 13-17.

[9] Shurong, Z.; Jinglong, H.; Dahua, T. Study on dehydrocyclization and aromatization process over ZnHZSM-5 catalyst. Petrol. Process. Petrochem. (China), 2001, 32(6), 60-63.

[10] Pop, G.; Ivanus, G.; Boteanu, S.; Tomi, P.; Pop, E. US 19794172816 , 1979

[11] Kolts, J. H. US 19864621163, 1986.

[12] Kolts, J. H.; Delzer G. A. US 1987 4705769, 1987.

[13] Andersen, J.; Fischer, F.; Rostrup, N. J.; Wrisberg, J. US 19753872179 , 1975.

[14] Kolombos, A. J.; McNeice, D.; Wood, D. C. U.S. Patent 1978 4087350, 1978.
[15] Yu, L.; Yingqiang, Z.; Na, L. Haiyan, W.; Jun, M.; Yongxing, Z. Development of process and catalyst of low olefin aromatization. $J$. Fushun Petrol. Inst. (China), 2002, 22(1), 23-8.

[16] Pant, K. K.; Kunzru, D. Catalytic Pyrolysis of n-Heptane. Ind. Eng. Chem. Res., 1997, 36, 2059-65.

[17] Pant, K. K.; Kunzru, D. Catalytic Pyrolysis of Methylcyclohexane: Kinetics and Modeling. Chem. Eng. J., 1998, 70, 47-54.

[18] eekman, J.; Nace, D. W. Kinetics of catalytic cracking selectivity in fixed. AICHE J., 1970, 16(3), 397-404.

[19] Jacob, S.M.; Gross, B.; Voltz, S.E.; Weekman, V.W. A lumping and reaction scheme for catalytic cracking. AICHE J., 1976, 22(4), 701-13.

[20] Chaogang, X.; Yuhua, L.; Yamin, W. Study on the aromatization reaction of FCC gasoline. Petrol. Process. Petrochem. (China), 1999, 30(11), 6-9.

[21] Shixiong, L. Petroleum processing and engineering. Petroleum Industry Press; Beijing, 1998.

(C) Hongjun You; Licensee Bentham Open.

This is an open access article licensed under the terms of the Creative Commons Attribution Non-Commercial License (http://creativecommons.org/licenses/by$\mathrm{nc} / 3.0 /$ / / which permits unrestricted, non-commercial use, distribution and reproduction in any medium, provided the work is properly cited. 